\title{
The Surface Structure and Thermal Properties of Novel Polymer Composite Films Based on Partially Phosphorylated Poly(vinyl alcohol) with Aluminum Phosphate
}

\author{
Asmalina Mohamed Saat ${ }^{1,2}$ and Mohd Rafie Johan ${ }^{2}$ \\ ${ }^{1}$ Universiti Kuala Lumpur, Malaysian Institute of Marine Engineering Technology, 32200 Lumut, Perak, Malaysia \\ ${ }^{2}$ Nanomaterials Engineering Research Group, Advanced Materials Research Laboratory, Department of Mechanical, \\ Faculty Engineering, Universiti Malaya, 50603 Kuala Lumpur, Malaysia
}

Correspondence should be addressed to Asmalina Mohamed Saat; asmalina@unikl.edu.my

Received 19 March 2014; Accepted 12 August 2014; Published 20 November 2014

Academic Editor: Levent Ballice

Copyright (C) 2014 A. Mohamed Saat and M. R. Johan. This is an open access article distributed under the Creative Commons Attribution License, which permits unrestricted use, distribution, and reproduction in any medium, provided the original work is properly cited.

\begin{abstract}
Partially phosphorylated polyvinyl alcohol (PPVA) with aluminum phosphate $\left(\mathrm{ALPO}_{4}\right)$ composites was synthesized by solution casting technique to produce (PPVA $)_{100-y}-\left(\mathrm{ALPO}_{4}\right)_{y}(y=0,1$, and 2). The surface structure and thermal properties of the films were characterized using Fourier transform infrared (FTIR) spectroscopy and thermogravimetric analysis (TGA). The results showed that the films have higher thermal stability with strong bonding between PPVA and $\mathrm{ALPO}_{4}$.
\end{abstract}

\section{Introduction}

The development of new polymer-inorganic composite materials has garnered much interest over the years due to their unique microstructures and physical and chemical properties, which are markedly different from other materials. Polyvinyl alcohol (PVA) is one of the most important polymeric materials in the industry as it is environmentally friendly and of low cost. PVA is a hydrophilic polymer which is frequently used as a matrix for a variety of inorganic particles. PVA provides a convenient route to prepare composites whereby the inorganic particles are dispersed to a high degree of uniformity and fineness. The addition of polyacids to water-soluble PVA produces hydrogen bonded complexes. In the case of strong phosphoric acids (PA), the reaction of PVA may produce partial reactions to cyclic phosphate esters [1]. The remaining replaceable hydrogen of the cyclic phosphate groups is ionized in water and the esterified polymer behaves as a polyelectrolyte. Furthermore, there is physical rubbery after esterification [2]. The phosphorylation of PVA with phosphoric acid (PA) in producing partially phosphorylated poly(vinyl alcohol) (PPVA) has attracted considerable interest in the applications such as fire-retardant materials [3-8], electrolyte [2, 9-12], membranes [13-15], metal chelating [1618], paper making [19], sensors [20-23], synthetic bones/teeth [17, 24], and nanoparticle/nanocomposite [25-28].

PPVA increases the amorphous structure of the polymer by decreasing its glass transition temperature $\left(T_{g}\right)$ and melting temperature $\left(T_{m}\right)$ [29]. PPVA complexes possess favourable properties such as good film forming, ion exchange, conductivity, chemical resistance, and flammability. Aluminum phosphate $\left(\mathrm{ALPO}_{4}\right)$ is used industrially as a high temperature dehydrating agent. In addition, $\mathrm{ALPO}_{4}$ also serves as a fluxing agent, binder, and catalyst in organic synthesis. $\mathrm{ALPO}_{4}$ exhibits a rich structural diversity in both dense and crystalline microporous series framework.

In this paper, the synthesis of PPVA-ALPO 4 composite films is described and their surface structures are examined. The thermal decomposition behaviour of PPVA-ALPO composites films is also investigated and compared with the decomposition characteristics of pure PVA. 


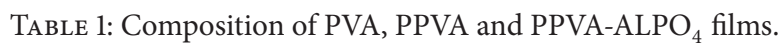

\begin{tabular}{lcccc}
\hline Sample code & PVA $(\mathrm{M})$ & PA (M) & PA/PVA (R) & ALPO $_{4}(\% \mathrm{wt})$ \\
\hline F0 & 0.15 & - & - & - \\
F1 & 0.15 & 0.0172 & 0.1150 & - \\
F2 & 0.15 & 0.0345 & 0.2299 & - \\
F3 & 0.15 & 0.0517 & 0.3449 & - \\
F4 & 0.15 & 0.0690 & 0.4599 & - \\
F5 & 0.15 & 0.0862 & 0.5748 & - \\
F3C1 & 0.15 & 0.0517 & 0.3449 & 1 \\
F3C2 & 0.15 & 0.0517 & 0.3449 & 2 \\
\hline
\end{tabular}

\section{Materials and Methodology}

PVA and PA/ortho-PA (85\%) were supplied by R\&M Chemicals while $\mathrm{ALPO}_{4}$ was obtained from Sigma-Aldrich. The first step in producing the polymer composites involved modifying the PVA surface. The fabrication system consisted of three-neck round-bottom flask, thermometer, heating mantel, magnetic stirrer, and reflux vessel. Following this, $6.6 \mathrm{~g}$ of PVA, deionized water, and PA was added into the three-neck round-bottom flask [28, 30]. The mixture was dissolved by heating at $90^{\circ} \mathrm{C}$ for 30 minutes and reflux was carried out by continuous stirring for 1 hour; $\mathrm{ALPO}_{4}$ was then added to produce the composites and the solution was maintained at $80-90^{\circ} \mathrm{C}$ under continuous stirring for 1 hour. The composition of various films is summarized in Table 1.

The complexation and chemical properties of all samples were analyzed using Perkin Elmer System 2000 Fourier transform infrared (FTIR) spectrometer with a scanning range of $4000-400 \mathrm{~cm}^{-1}$. The thermal properties of the samples were recorded using Mettler Toledo TGA/SDTA851 thermogravimetric analyzer with temperature range of $25-$ $1000^{\circ} \mathrm{C}$.

\section{Results and Discussion}

3.1. FTIR Analysis of PVA and PPVA Films. The FTIR spectra for PVA/PPVA films (Samples F0-F5) are shown in Figure 1. The spectrum for pure PVA (F0) shows $\nu \mathrm{O}-\mathrm{H}$ $\left(3288 \mathrm{~cm}^{-1}\right), \mathrm{C}-\mathrm{H}\left(2925 \mathrm{~cm}^{-1}\right), \mathrm{C}=\mathrm{O}\left(1722 \mathrm{~cm}^{-1}\right), \mathrm{CH}_{2}(1423$ and $\left.1247 \mathrm{~cm}^{-1}\right), \mathrm{C}-\mathrm{O}-\mathrm{H}\left(1080 \mathrm{~cm}^{-1}\right)$ [7, 30], and skeleton (836 and $599 \mathrm{~cm}^{-1}$ ) [2] bands at the fingerprint region. The peak at $1722 \mathrm{~cm}^{-1}$ corresponds to the $\mathrm{C}=\mathrm{O}$ stretching mode of the ester groups and occurs mostly in partially hydrolyzed PVA [31]. The stretching vibrations of carbonyl and/or carboxyl groups in the minor acetate groups $(-\mathrm{CO}(\mathrm{O}) \mathrm{CH})$ in the PVA contribute to the existence of this peak [6]. In addition, there are intrainter molecular hydrogen bonds between the acetate groups in the PVA and adjacent $\mathrm{OH}$ group [32, 33].

It can be observed that the peaks for $\mathrm{OH}, \mathrm{P}=\mathrm{O}$, and $\mathrm{C}-$ $\mathrm{O}-\mathrm{P}$ bands disappear at higher concentrations of PA. Even though the intensity of the $\mathrm{OH}$ peak decreases abruptly upon the addition of PA, this intensity increases with an increase of PA due to the absorption of moisture by the film. The $\mathrm{OH}$ peak then broadens which indicates the interaction between PVA and PA [31] due to their phase separation and

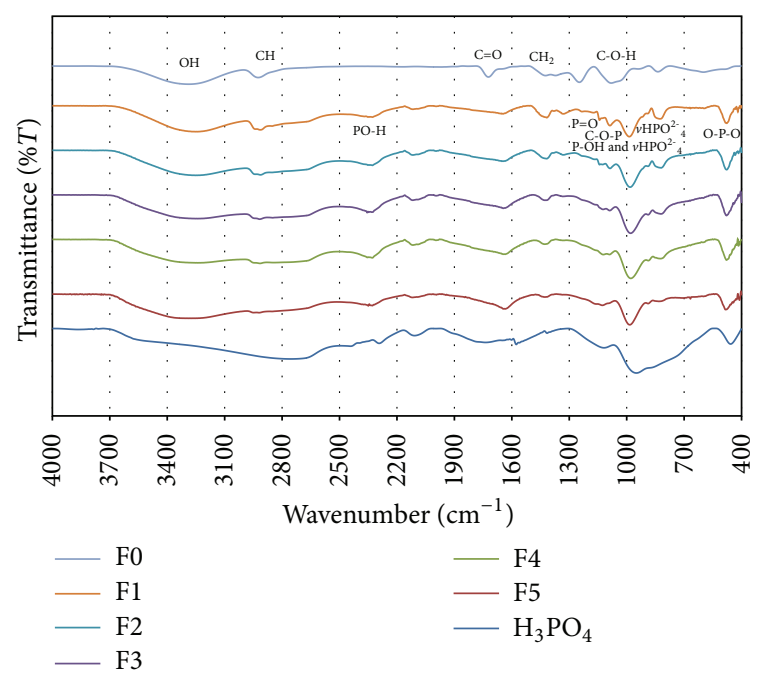

FIGURE 1: FTIR spectra of PVA and PPVA films.

dehydration at higher acid concentrations. Variations in the $\mathrm{P}=\mathrm{O}$ peak at $1329-1331 \mathrm{~cm}^{-1}$ for Samples $\mathrm{F} 0-\mathrm{F} 2$ are due to hydrogen bonding and the $\mathrm{P}=\mathrm{O}$ peak disappears completely for Samples F3-F5. The C-OH peak disappears, whereas the $\mathrm{C}-\mathrm{O}$ peak appears $[7,8,30]$ upon the addition of PA. The disappearance of the $\mathrm{C}-\mathrm{OH}$ peak is attributed to the chemical modifications of PVA by PA. The $\mathrm{C}-\mathrm{O}-\mathrm{P}$ peak shifts to higher wavenumber and attenuates due to hydrogen bonding. The overlapping of $v \mathrm{P}-\mathrm{O}(\mathrm{C})$ and $v \mathrm{HPO}_{4}{ }^{2-}$ vibration groups [28, 30,31 ] produces an intense peak. The $\mathrm{C}-\mathrm{O}-\mathrm{P}$ groups become weaker at higher concentrations of PA due to the formation of hydrogen bonds $\left(v \mathrm{HPO}_{4}{ }^{2-}\right)$.

The peak intrinsic to $\mathrm{C}-\mathrm{H}, \mathrm{PO}-\mathrm{H}, \mathrm{C}=\mathrm{C}$, and $\mathrm{C}-\mathrm{O}-\mathrm{P}$ overlap with $\mathrm{P}-\mathrm{O}, \mathrm{P}-\mathrm{O}$, and $\mathrm{O}-\mathrm{P}-\mathrm{O}$ peaks is more apparent with an increase in $\mathrm{PA}$ concentrations. The $\mathrm{C}-\mathrm{H}$ peak shifts to a higher wavenumber for Sample F3, whereas this peak shifts to a lower wavenumber for Sample F4. However, the peaks at 1634 and $1273 \mathrm{~cm}^{-1}$ which are not shifted correspond to the bending mode of water molecules [31] as well as PVA dehydration at higher concentration of PA [30]. The highest wavenumber recorded for the shift in $\mathrm{O}-\mathrm{H}$ peak is $2355 \mathrm{~cm}^{-1}$ (Sample F3), whereas the lowest wavenumber recorded for this shift is $2338 \mathrm{~cm}^{-1}$ (Sample F4). It can be observed that there is increase in the intensity of peaks for the $\mathrm{P}-\mathrm{OH}$ band [30] as well as in an overlapping of $\mathrm{C}-\mathrm{O}-\mathrm{P}$ and $\mathrm{P}-\mathrm{O}, \mathrm{P}-\mathrm{O}$, and $\mathrm{O}-\mathrm{P}-\mathrm{O}$ bands at higher concentrations of $\mathrm{PA}$, which is attributed to the higher number of free PA molecules in the films. These peaks shift to higher wavenumbers. The peaks at $986-978 \mathrm{~cm}^{-1}$ belong to the $\mathrm{P}-\mathrm{O}$ groups which originated from $\left(\mathrm{H}_{2} \mathrm{PO}_{4}\right)^{-}$and $v \mathrm{HPO}_{4}{ }^{2-}[28,30,31]$. The emergence of the $\mathrm{P}-\mathrm{O}$ peak can be observed at $825 \mathrm{~cm}^{-1}$ for Sample F2, whereas the $v \mathrm{HPO}_{4}{ }^{2-}$ peak shifts to a lower wavenumber as the $\mathrm{PA}$ concentration increases. However, the $\mathrm{O}-\mathrm{P}-\mathrm{O}$ peak at $477 \mathrm{~cm}^{-1}$ for the PPVA sample shifts to a higher wavenumber with an increase in PA concentration. The deformation of $\mathrm{O}-\mathrm{P}-\mathrm{O}$ as well as vibration modes in $\mathrm{PO}_{4}{ }^{3-}$ can be clearly observed [34]. 


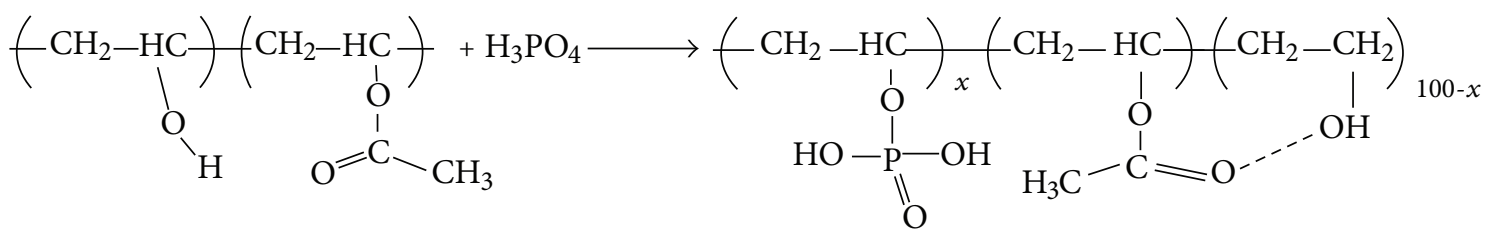

(a)<smiles>CC=CC(C)(C)CC(CC(C)(C)C)OP(=O)(O)O</smiles>

(b)

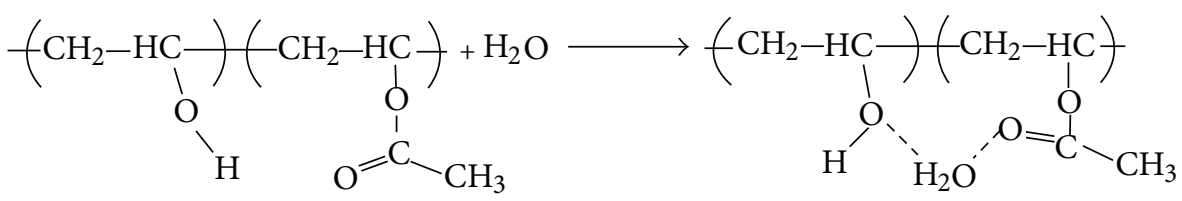

(c)

FIGURE 2

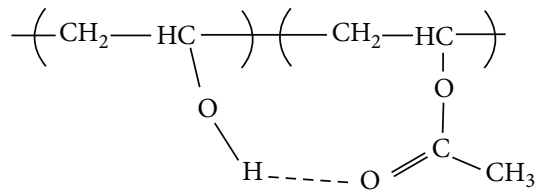

FIgURE 3: Intramolecular hydrogen bonding [33].

The maximum bonding number for PA to PVA occurs at a mole ratio of $R=0.33$ (Figure 2(a)), which means that the three functional groups of PVA can react with one unit of PA. All protons are lost during the formation of $\mathrm{C}-\mathrm{O}-\mathrm{P}$ bonds at this value of $R$. However, it is expected that there will be free unreacted PVA groups for $R$ values less than 0.33 , due to insufficient free PA molecules. However, there will be additional free PA functional groups for $R$ values above 0.33 , giving none of the free PVA functional groups which will undergo a reaction. In this case, the free PA units will react with available $\mathrm{OH}$ groups, forming hydrogen bonds which will weaken and break up the $\mathrm{C}-\mathrm{O}-\mathrm{P}$ bond. An increase in $\mathrm{HPO}_{4}{ }^{2-}$ also weakens the $\mathrm{C}-\mathrm{O}-\mathrm{P}$ bonds. These bonds are stabilized by losing a proton $\mathrm{H}^{+}$and forming a $\mathrm{C}=\mathrm{C}$ bond which leads to dehydration, as observed in Sample F4. In this case, the $\mathrm{C}-\mathrm{O}-\mathrm{P}$ band shifts to a higher wavenumber $\left(1122 \mathrm{~cm}^{-1}\right)$ with an increase in intensity and a decrease peak width. However, the $\mathrm{C}=\mathrm{C}$ band for Sample F4 shifts to a lower wavenumber with a decrease in intensity and an increase in peak width due to dehydration, while crosslinking of phosphorylation occurs in Samples F1-F3.

The nonlinear increase of PVA with PA molecules is attributed to the acetate groups in the PVA as well as plasticization effect of water on PVA [35]. However, the nonlinear increase tends to level off when $R$ exceeds 0.33 or if the

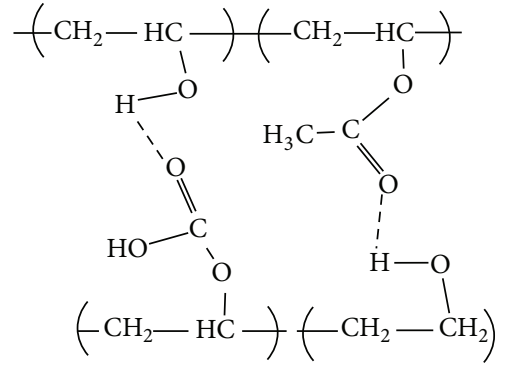

FIgURE 4: Intermolecular hydrogen bonding [33].

molar concentration of PA is $1.76 \mathrm{M}$ [7]. Figure 2(a) shows the reaction between PVA and PA in order to produce partially phosphorylated PVA. The partially phosphorylated PVA consists of phosphorylated and unphosphorylated $\mathrm{OH}$ units as well as acetate groups with intermolecular bonding with adjacent $\mathrm{OH}$. This agrees well with the FTIR results presented in Figure 3, in which partially phosphorylated PVA (Figure 2(a)) is produced for a mole ratio of $R \leq 0.33$ whereas dehydration of PVA (Figure $2(b)$ ) is produced for a mole ratio of $R>0.33$ [30]. Dehydration of PVA produced conjugate double bond of the phosphonate groups in PVA [7]. The dehydration gel component increases, whereas the partially phosphorylated component decreases with increasing PA concentration due to the attenuation of $\mathrm{C}-\mathrm{O}-\mathrm{P}$ bond.

Figure 2(c) shows the $\mathrm{C}=\mathrm{O}$ bond of partially hydrolyzed PVA, whereby bonding occurs with the $\mathrm{OH}$ groups in water [35]. The acetate groups only appear in pure PVA film (Sample F0), whereas the acetate groups have inter/intramolecular bond with available hydrogen in the PPVA films. The intramolecular and intermolecular hydrogen bonding is shown in Figures 3 and 4, respectively. 


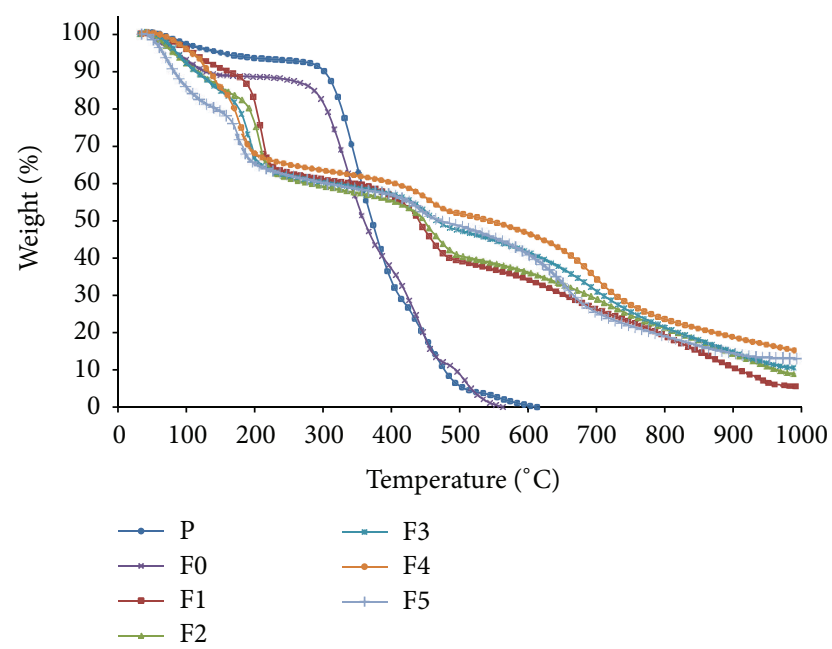

FIgURe 5: TGA curves of PVA powder (P), PVA (F0), and PPVA (F1-F5) films.

3.2. TGA Analysis of PVA and PPVA Films. The TGA curves of PVA powder (P) and PVA-PPVA films (Samples F0-F5) are shown in Figure 5. The first weight loss is observed below $100^{\circ} \mathrm{C}$, which is due to the evaporation of moisture. The first stage of degradation occurs between 130 and $270^{\circ} \mathrm{C}$, whereby PVA begins to form a double bond as shown in Figure 6 as well as it start to decompose by elimination of water and acetate groups [35]. The partially hydrolyzed PVA releases acetic acids at a lower temperatures and decomposes at a higher temperature $\left(330^{\circ} \mathrm{C}\right)$ [36]. The second stage of degradation occurs between 270 and $460^{\circ} \mathrm{C}$ due to the breakup of PVA backbones as well as degradation of acetate groups [35]. This stage is of particular interest in evaluating the thermal stability of the polymer. The third stage of degradation occurs between 460 and $600^{\circ} \mathrm{C}$, whereby the PVA decomposes into impurities and other volatile materials. The PVA decomposes completely at $600^{\circ} \mathrm{C}$.

The thermal degradation of PPVA produces a condensed phase mechanism which involves dehydration, crosslinking, and char formation [3]. The TGA curves for all PPVA samples are shown in Figure 5, and it can be observed that the PPVA samples have higher weight residue compared to PVA powder (P) and pure PVA film (F0). The degradation of complexed PPVA films begins at temperature below $100^{\circ} \mathrm{C}$ (first stage) due to the evaporation of water [37]. The second stage of degradation occurs between 120 and $190^{\circ} \mathrm{C}$ due to the elimination of water and volatiles products as well as formation of diphosphate [38] and triphosphate [7] and breakup of complexed PPVA [2]. The second stage of degradation occurs between 190 and $460^{\circ} \mathrm{C}$ due to the spontaneous degradation of PPVA and breakup of PVA backbones [35]. The decomposition of PVA begins at $460-700^{\circ} \mathrm{C}$ while the residue oxidation occurs between 700 and $950^{\circ} \mathrm{C}$ [8]. Char formation occurs during the final stage of degradation and the unoxidized residue remains at temperatures above $950^{\circ} \mathrm{C}$ [8].

Spontaneous degradation of complexed PPVA films occurs at $190^{\circ} \mathrm{C}$ upon the addition of PA and the temperature continues to decreases to $170^{\circ} \mathrm{C}$ for the F5 film. Pyrolysis occurs at $168^{\circ} \mathrm{C}$ which is due to acid, whereas crosslinking between the phosphate groups and PVA occurs below $168^{\circ} \mathrm{C}$ [6]. The total degradation of complexed PPVA occurs at $950^{\circ} \mathrm{C}$ compared to pure PVA $\left(600^{\circ} \mathrm{C}\right)$. Major degradation of PVA occurs during the second stage which constitutes $74 \%$ of the weight loss. In contrast, major degradation complexed PPVA occurs during the first stage with $32 \%$ weight loss. This clearly proves that Sample F3 attains the maximum bonding of PVA and PPVA. Below $90^{\circ} \mathrm{C}$, PVA reacts with PA to form partially phosphorylated PVA known as polyvinyl alcohol phosphate (PVA-P) and tends to produce polyvinyl diphosphate (PVA-DP) at temperature above $90^{\circ} \mathrm{C}$ [38]. PVA$\mathrm{P}$ is hydrophilic, whereas PVA-DP is hydrophobic. PVA-P can be produced using a reaction time less than 3 hours, whereas PVA-DP requires reaction times of more than 4 hours. PVA cannot be dissolved completely at temperatures less than $90^{\circ} \mathrm{C}$. Consequently, the $\mathrm{OH}$ groups in PVA are not activated due to hydrogen bonding, which leads to esterification of PA to PVA at the surface of the PVA powder. PVA-P is mainly produced in Sample F3 in which a high weight loss can be observed due to water elimination and crosslinking of PVA-P to PVA-DP. The formation of PVA-P (hydrophilic) and PVA-DP (crosslink/hydrophobic) is influenced by the amount of water, reaction temperature, and reaction time. The phosphate groups that react with PVA in the autoclave yield favourable properties at reaction temperature $120^{\circ} \mathrm{C}$ compared to $70-90^{\circ} \mathrm{C}$ [26]. However, conjugated double bonds are formed when the PVA is heated above $120^{\circ} \mathrm{C}$ after the polymer experiences rapid chain-stripping elimination of water [25]. The weight residue increases in complexed PPVA. However the addition of PA reduces weight residue in the first stage of PPVA degradation. The degradation process of complexed PVA is given in Figure 7.

It can be seen that there is $14 \%$ weight residue due to water elimination and breakup of complexes for the PVA film upon the addition of $25 \mathrm{~mL}$ of water. Even though the amount of water decreases with an increase in PA concentration, the total solution (mixture of PA and deionized water) remains $25 \mathrm{~mL}$ which is the case for Sample F1. However, the weight residue for Sample F2 increases as the amount of water added decreases due to the formation of complexed PPVA which absorbs more moisture. Maximum bonding between PA and PVA occurs for Sample F3 with less water absorption. The maximum weight residue occurs during the first stage of degradation due to breakup of complexed PPVA. The PVA experiences dehydration from high concentrations of PA for Sample F4, whereby less water is absorbed. The plasticization effects of PA on PVA tends to level off and phase separation occurs at higher concentration of PA which is added into Sample F5 [39]. It is also observed that Sample F5 is sticky, wet, and oily.

3.3. FTIR Analysis of PPVA and PPVA-ALPO ${ }_{4}$ Films. The FTIR spectra for PPVA and PPVA-ALPO ${ }_{4}$ composite films are shown in Figure 8. The peak at 1088, 979, and $480 \mathrm{~cm}^{-1}$ for PPVA film (Sample F3) shifts to a lower wavenumber of 1086,977 , and $475 \mathrm{~cm}^{-1}$ for the PPVA-ALPO 4 film (Sample $\mathrm{F} 3 \mathrm{C} 2$ ) with a higher weight percent of $\mathrm{ALPO}_{4}$. The peaks are assigned to $\mathrm{C}-\mathrm{O}-\mathrm{P}, \mathrm{P}-\mathrm{OH}, v \mathrm{HPO}_{4}{ }^{2-}$, and $\mathrm{O}-\mathrm{P}-\mathrm{O}$ 


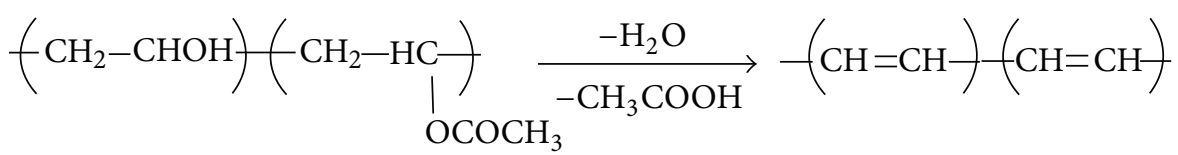

FiguRe 6

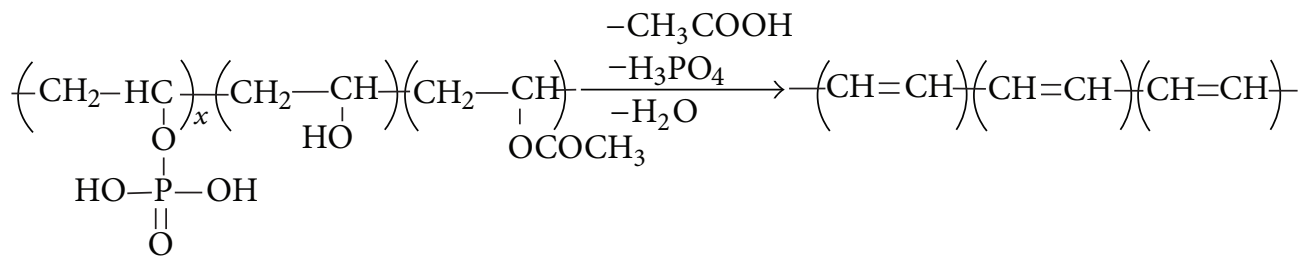

Figure 7

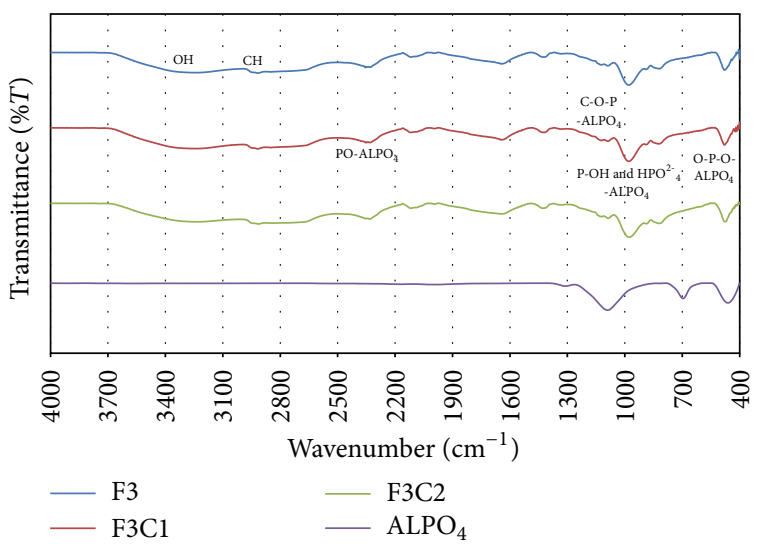

FIGURE 8: FTIR spectra of PPVA-ALPO ${ }_{4}$ composite films.

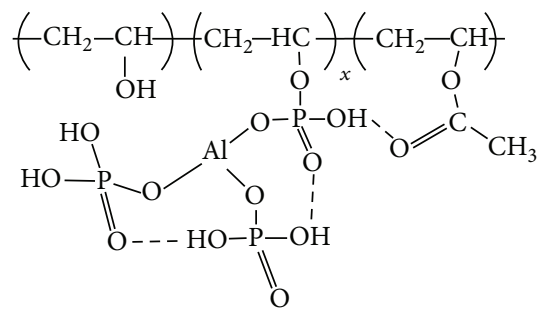

FIGURE 9: Model structure of PPVA-ALPO 4 network.

bands, respectively, and indicate the interaction between PPVA and $\mathrm{ALPO}_{4}$. A similar trend was also observed for phosphate bonding interaction at C-O-P bands $(1230,1196$, and $1166 \mathrm{~cm}^{-1}$ ), overlapping of $\mathrm{C}-\mathrm{O}-\mathrm{P}$ and $\mathrm{P}-\mathrm{O}$ bands $\left(930-970 \mathrm{~cm}^{-1}\right)$, and $\mathrm{O}-\mathrm{P}-\mathrm{O}$ bands $\left(603,565 \mathrm{~cm}^{-1}\right)$ with aluminum content [34]. The peak for the $\mathrm{O}-\mathrm{P}-\mathrm{O}$ band shows a decrease in intensity and broadening of peak width with an increase in $\mathrm{ALPO}_{4}$, which indicates a strong interaction between PPVA and $\mathrm{ALPO}_{4}$ by the formation of O-P-O$\mathrm{ALPO}_{4}$ and C-O-P-ALPO 4 bonds, as shown in Figure 9. The FTIR results are summarized in Table 2.

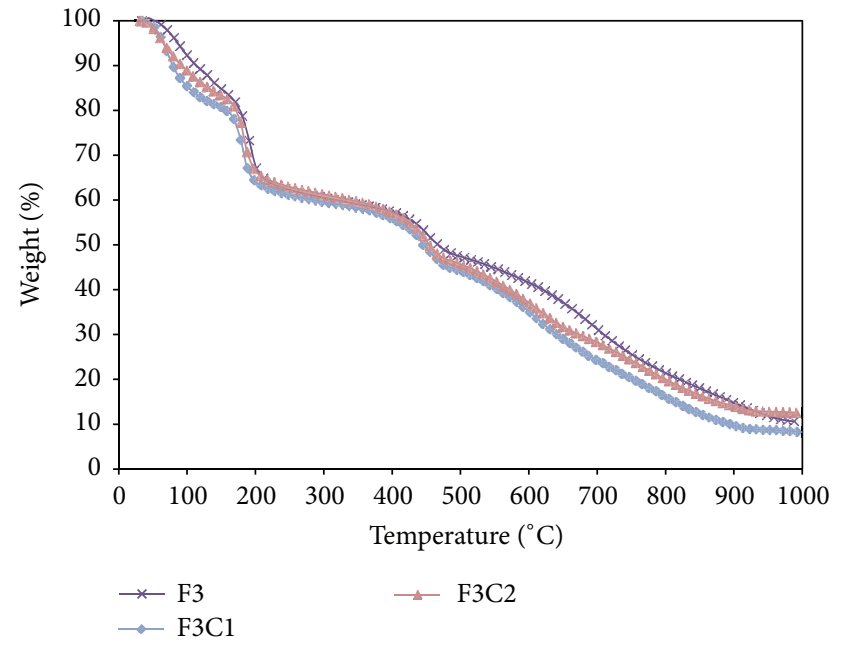

Figure 10: TGA curves for PPVA film (Sample F3) and PPVA$\mathrm{ALPO}_{4}$ composite films (Samples F3C1 and F3C2).

3.4. TGA Analysis of PPVA and PPVA-ALPO Films. The TGA curves for PPVA and composite PPVA- $\mathrm{ALPO}_{4}$ composite films are presented in Figure 10. It can be observed that the PPVA and PPVA- $\mathrm{ALPO}_{4}$ films have higher weight residue compared to the PPVA and PVA samples which is attributed to the higher crosslinking productions of diphosphate and triphosphate as well as reactions with $\mathrm{ALPO}_{4}$. This, in turn, increases char formation, which remains unoxidized in the waste. The thermal stability of the PPVA-ALPO ${ }_{4}$ composite film is improved compared to pure PVA and PPVA films due to the interfacial bonding between $\mathrm{ALPO}_{4}$ and PPVA. The pure PVA film is stable up to $260^{\circ} \mathrm{C}$, whereas the PPVA and PPVA-ALPO ${ }_{4}$ samples are stable up to $190^{\circ} \mathrm{C}$. Thermal decomposition occurs in two steps after water loss. Thermal decomposition begins at $220^{\circ} \mathrm{C}$ and ends at $492^{\circ} \mathrm{C}$, which corresponds to the structure of the PVA. The first stage of degradation occurs at a faster rate, whereas the second stage of degradation is a slow process. The degradation of PPVA 


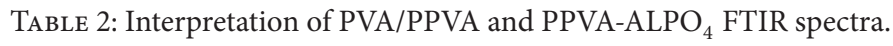

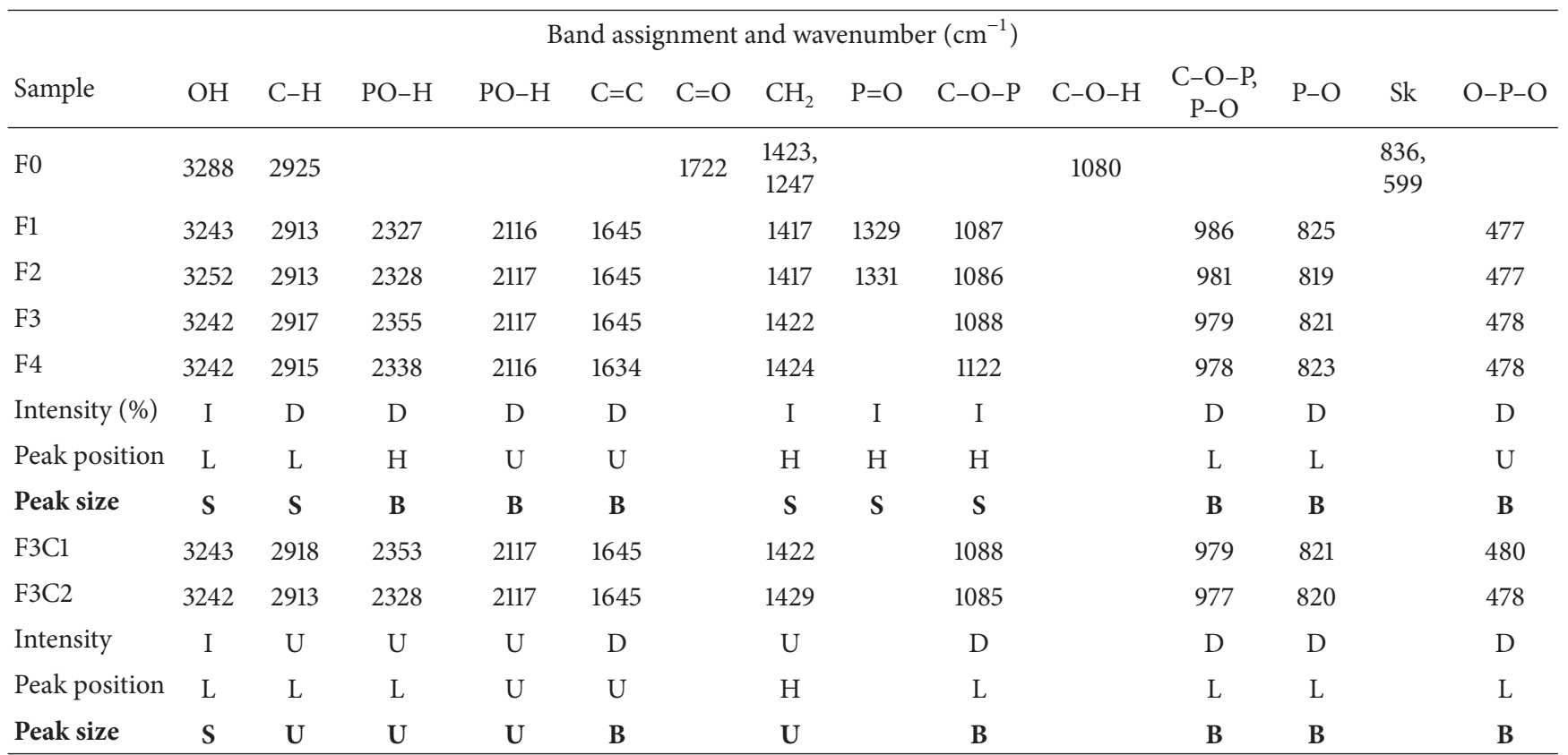

Sk = skeletal, intensity, $\mathrm{I}=$ increase, $\mathrm{D}=$ decrease, peak position, $\mathrm{L}=$ shift to lower wavelength, $\mathrm{H}=$ shift to higher wavelength, $\mathrm{U}=\mathrm{unshifted}$, peak size, $\mathrm{B}=$ increase, $\mathrm{S}=$ decrease, $\mathrm{U}=$ unchanged.

and PPVA-ALPO $\mathrm{PO}_{4}$ begins at a lower temperature compared to PVA. The amount of weight residue for PPVA-ALPO com- $_{4}$ posite film is higher compared to PPVA and PVA films.

\section{Conclusion}

In this study, polymer-inorganic composites have been synthesized successfully by solution casting technique. The FTIR results reveal that the maximum bonding between PVA and PA occurs in the F3 film. The PPVA-ALPO ${ }_{4}$ composite film exhibits enhanced thermal properties compared to PPVA and PVA films. Weight loss begins at a lower temperature in

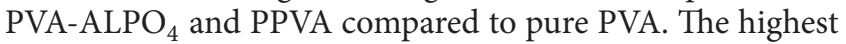
weight residue is obtained after thermal decomposition in air compared to PPVA and PVA. The thermal stability of PPVA and PPVA-ALPO ${ }_{4}$ films is significantly higher than that for pure PVA which proves a strong bonding between PPVA and aluminum phosphate.

\section{Conflict of Interests}

The authors declare that there is no conflict of interests regarding the publication of this paper.

\section{Acknowledgments}

The authors graciously acknowledge the financial support granted by the UM PPP Grant (nos. PS115-2010B and PV129/2012A) as well as UM High Impact Research Grant (C/625/HIR/MOHE/ENG/12). The first author would like to extend her appreciation to University Kuala Lumpur for their financial support and for offering study leave in order to complete this study.

\section{References}

[1] J. G. Pritchard, Poly(Vinyl Alcohol) : Basic Properties and Uses, Macdonald \& Company, London, UK, 1970.

[2] P. R. Somani, R. Marimuthu, A. K. Viswanath, and S. Radhakrishnan, "Thermal degradation properties of solid polymer electrolyte (poly(vinyl alcohol) + phosphoric acid)/methylene blue composites," Polymer Degradation and Stability, vol. 79, no. 1, pp. 77-83, 2003.

[3] P. Joseph and S. Tretsiakova-Mcnally, "Reactive modifications of some chain- and step-growth polymers with phosphoruscontaining compounds: effects on flame retardance-a review," Polymers for Advanced Technologies, vol. 22, no. 4, pp. 395-406, 2011.

[4] D.-L. Wang, Y. Liu, C. Zhao, Y. Mou, and Y. Wang, "A novel intumescent flame-retardant system containing metal chelates for polyvinyl alcohol," Polymer Degradation and Stability, vol. 92, no. 8, pp. 1555-1564, 2007.

[5] S. I. Sanchez, "The role of phosphorus in fire retardant polymers," in Materials Chemistry Seminar Abstracts, 2007.

[6] Z. Yue, J. Economy, and C. L. Mangun, "Preparation of fibrous porous materials by chemical activation $2 . \mathrm{H}_{3} \mathrm{PO}_{4}$ activation of polymer coated fibers," Carbon, vol. 41, no. 9, pp. 1809-1817, 2003.

[7] M. Banks, J. R. Ebdon, and M. Johnson, "Influence of covalently bound phosphorus-containing groups on the flammability of poly(vinyl alcohol), poly(ethylene-co-vinyl alcohol) and lowdensity polyethylene," Polymer, vol. 34, no. 21, pp. 4547-4556, 1993.

[8] N. Inagaki, K. Tomiha, and K. Katsuura, "Studies on the thermal degradation of phosphorus containing polymers: 7. Thermal degradation of phosphorylated poly(vinyl alcohol)," Polymer, vol. 15 , no. 6 , pp. $335-338,1974$. 
[9] L. Yuan, X. Lu, X. Xiao et al., "Flexible solid-state supercapacitors based on carbon nanoparticles $/ \mathrm{MnO}_{2}$ nanorods hybrid structure," ACS Nano, vol. 6, no. 1, pp. 656-661, 2012.

[10] G. K. Prajapati, R. Roshan, and P. N. Gupta, "Effect of plasticizer on ionic transport and dielectric properties of $\mathrm{PVAH}_{3} \mathrm{PO}_{4}$ proton conducting polymeric electrolytes," Journal of Physics and Chemistry of Solids, vol. 71, no. 12, pp. 1717-1723, 2010.

[11] G. K. Prajapati and P. N. Gupta, "Study of ionic conductivity, dielectric characteristics and capacitance measurement of $\gamma$ irradiated conducting polymeric electrolytes," Phase Transitions: A Multinational Journal, vol. 82, no. 1, pp. 1-9, 2009.

[12] P. N. Gupta, "Thermal properties and electrochromic behaviour of PVA complexed electrolytes using PEG," Indian Journal of Pure and Applied Physics, vol. 46, no. 9, pp. 657-659, 2008.

[13] F. Ahmad and E. Sheha, "Preparation and physical properties of $(\mathrm{PVA})_{0.7}(\mathrm{NaBr})_{0.3}\left(\mathrm{H}_{3} \mathrm{PO}_{4}\right)_{x M}$ solid acid membrane for phosphoric acid-fuel cells," Journal of Advanced Research, vol. 4, no. 2, pp. 155-161, 2013.

[14] Y.-S. Ye, J. Rick, and B. Hwang, "Water soluble polymers as proton exchange membranes for fuel cells," Polymers, vol. 4, no. 2, pp. 913-963, 2012.

[15] U. Thanganathan, J. Parrondo, and B. Rambabu, "Nanocomposite hybrid membranes containing polyvinyl alcohol or poly(tetramethylene oxide) for fuel cell applications," Journal of Applied Electrochemistry, vol. 41, no. 5, pp. 617-622, 2011.

[16] E. Bayer, "Poly(vinyl alcohol) as Polymeric support for metal chelating phosphoric acid and derivatives," Die Angewandte Makromolekulare Chemie, vol. 113, pp. 141-152, 1983.

[17] Y. An, T. Koyama, K. Hanabusa et al., "Preparation and properties of highly phosphorylated poly(vinyl alcohol) hydrogels chemically crosslinked by glutaraldehyde," Polymer, vol. 36, no. 11, pp. 2297-2301, 1995.

[18] Y. An, T. Ushida, M. Suzuki, T. Koyama, K. Hanabusa, and H. Shirai, "Complex formation of partially phosphorylated poly(vinyl alcohol), with metal ions in aqueous solution," Polymer, vol. 37, no. 14, pp. 3097-3100, 1996.

[19] X. Chen, R. Huang, and R. Pelton, "The reinforcement of calcium carbonate filled papers with phosphorus-containing polymers," Industrial and Engineering Chemistry Research, vol. 44, no. 7, pp. 2078-2085, 2005.

[20] P. Somani, D. P. Amalnerkar, and S. Radhakrishnan, "Effect of moisture (in solid polymer electrolyte) on the photosensitivity of conducting polypyrrole sensitized by prussian blue in solidstate photocells," Synthetic Metals, vol. 110, no. 3, pp. 181-187, 2000.

[21] P. R. Somani, A. K. Viswanath, R. C. Aiyer, and S. Radhakrishnan, "Novel dye + solid polymer electrolyte material for optical humidity sensing," Organic Electronics: Physics, Materials, Applications, vol. 2, no. 2, pp. 83-88, 2001.

[22] P. R. Somani, A. K. Viswanath, R. C. Aiyer, and S. Radhakrishnan, "Charge transfer complex-forming dyes incorporated in solid polymer electrolyte for optical humidity sensing," Sensors and Actuators B, vol. 80, no. 2, pp. 141-148, 2001.

[23] F. Mizutani, S. Yabuki, Y. Sato, T. Sawaguchi, and S. Iijima, "Amperometric determination of pyruvate, phosphate and urea using enzyme electrodes based on pyruvate oxidase-containing poly(vinyl alcohol)/polyion complex-bilayer membrane," Electrochimica Acta, vol. 45, no. 18, pp. 2945-2952, 2000.

[24] Q. Yu and P. Carlsen, "Synthesis of polynucleotide analogs containing a polyvinyl alcohol backbone," Molecules, vol. 13, no. 3, pp. 701-715, 2008.
[25] M. Rajkumar, N. Meenakshi Sundaram, and V. Rajendran, "In-situ preparation of hydroxyapatite nanorod embedded poly(vinyl alcohol) composite and its characterization," International Journal of Engineering Science and Technology, vol. 2, pp. 2437-2444, 2010.

[26] P. Pramanik, "Some simple chemistry for exotic polymers," in Proceedings of the 17th International conference composite/nano engineering (ICCE '09), vol. 6, pp. 1-2, World Journal of Engineering, Honolulu, Hawaii, USA, 2009.

[27] N. Pramanik, S. Mohapatra, S. Alam, and P. Pramanik, "Synthesis of hydroxyapatite/poly(vinyl alcohol phosphate) nanocomposite and its characterization," Polymer Composites, vol. 29, no. 4, pp. 429-436, 2008.

[28] S. Mohapatra, N. Pramanik, S. K. Ghosh, and P. Pramanik, "Synthesis and characterization of ultrafine poly(vinylalcohol phosphate) coated magnetite nanoparticles," Journal of Nanoscience and Nanotechnology, vol. 6, no. 3, pp. 823-829, 2006.

[29] M. Suzuki, T. Yoshida, T. Koyama et al., "Ionic conduction in partially phosphorylated poly(vinyl alcohol) as polymer electrolytes," Polymer, vol. 41, no. 12, pp. 4531-4536, 2000.

[30] A. Iribarren, A. López-Marzo, and H. Lemmetyinen, "Absorption in polyvinyl alcohol phosphoric acids films under different processing conditions. Kinetic study," Revista Cubana de Quimica, vol. 21, pp. 3-9, 2009.

[31] Y. Jin, J. C. Diniz da Costa, and G. Q. Lu, "Proton conductive composite membrane of phosphosilicate and polyvinyl alcohol," Solid State Ionics, vol. 178, no. 13-14, pp. 937-942, 2007.

[32] W. A. Jabbar, N. F. Habubi, and S. S. Chiad, "Optical characterization of silver doped poly (vinyl alcohol) films," Journal of the Arkansas Academy of Science, vol. 64, pp. 101-105, 2010.

[33] R. F. Bhajantri, V. Ravindrachary, A. Harisha, V. Crasta, S. P. Nayak, and B. Poojary, "Microstructural studies on $\mathrm{BaCl}_{2}$ doped poly(vinyl alcohol)," Polymer, vol. 47, no. 10, pp. 3591-3598, 2006.

[34] H. Neuder, C. Sizemore, M. Kolody, R. Chiang, and C. Lin, "Molecular design of in situ phosphatizing coatings (ISPCs) for aerospace primers," Progress in Organic Coatings, vol. 47, no. 34, pp. 225-232, 2003.

[35] P. Alexy, D. Káchová, M. Kršiak, D. Bakoš, and B. Šimková, "Poly(vinyl alcohol) stabilisation in thermoplastic processing," Polymer Degradation and Stability, vol. 78, no. 3, pp. 413-421, 2002.

[36] B. J. Holland and J. N. Hay, "The thermal degradation of poly(vinyl acetate) measured by thermal analysis-Fourier transform infrared spectroscopy," Polymer, vol. 43, no. 8, pp. 22072211, 2002.

[37] K.-C. Gong and H. Shou-Cai, "Electrical properties of poly(vinyl alcohol) complexed with phosphoric acid," in $M R S$ Proceedings, vol. 135, 1989.

[38] F. Zhan, M. Liu, M. Guo, and L. Wu, "Preparation of superabsorbent polymer with slow-release phosphate fertilizer," Journal of Applied Polymer Science, vol. 92, no. 5, pp. 3417-3421, 2004.

[39] J. Jang and D. K. Lee, "Plasticizer effect on the melting and crystallization behavior of polyvinyl alcohol," Polymer, vol. 44, no. 26 , pp. 8139-8146, 2003. 

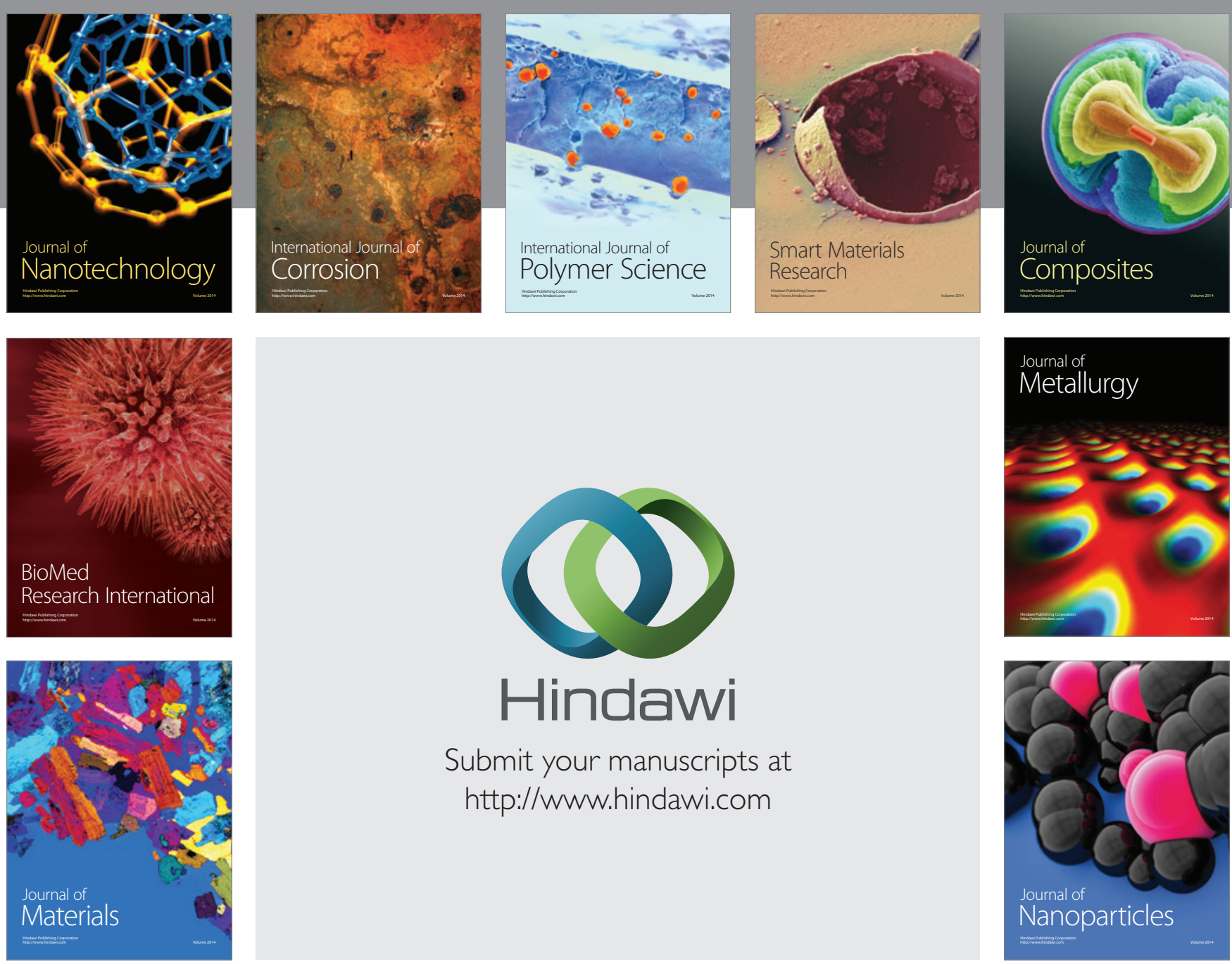

Submit your manuscripts at http://www.hindawi.com
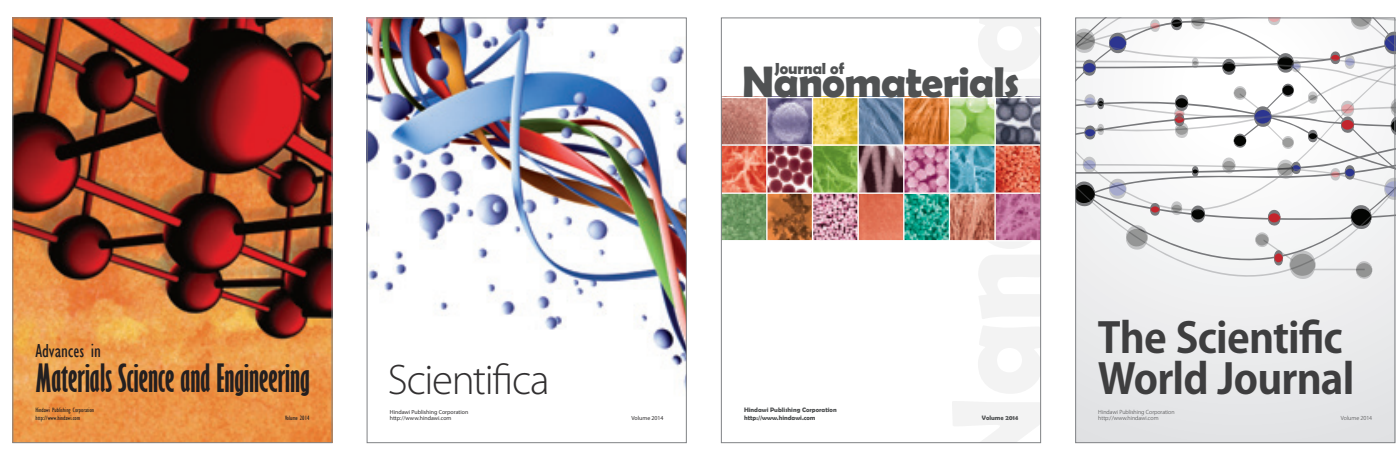

\section{The Scientific World Journal}
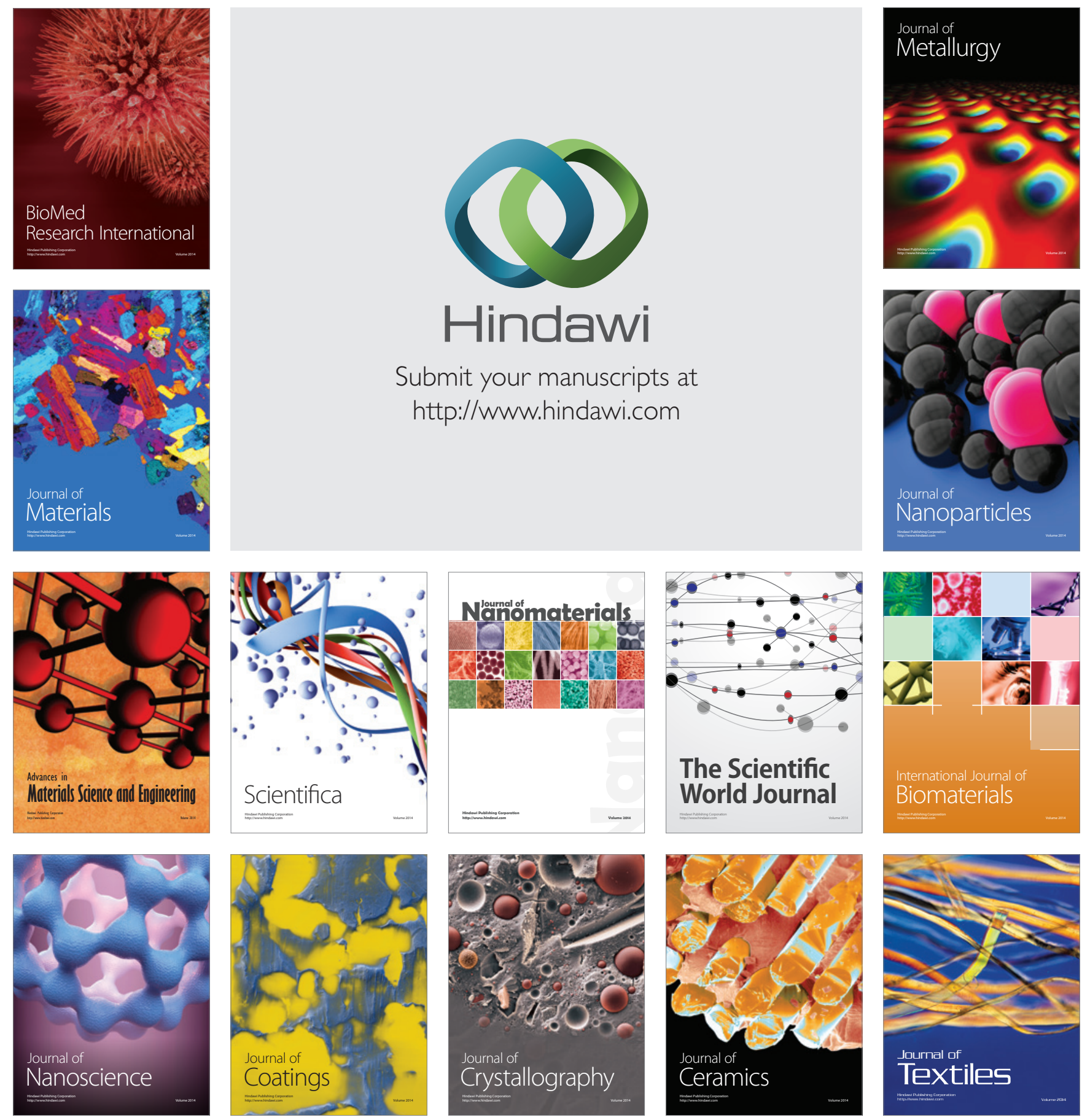